\title{
Halo effect of a weight-loss trial on spouses: the DIRECT-Spouse study
}

\author{
Rachel Golan ${ }^{1}$, Dan Schwarzfuchs ${ }^{2}$, Meir J Stampfer ${ }^{3}$ and Iris Shai ${ }^{1, *}$; for the \\ DIRECT group
}

${ }^{1} S$. Daniel Abraham International Center for Health and Nutrition, Department of Epidemiology and Health Systems Evaluation, Ben-Gurion University of the Negev, P.O. Box 653, Be'er-Sheva 84105, Israel: ${ }^{2}$ Nuclear Research Center Negev, Dimona, Israel: ${ }^{3}$ Brigham and Women's Hospital and Harvard Medical School, and the Departments of Epidemiology and Nutrition, Harvard School of Public Health, Boston, MA, USA

Submitted 13 November 2008: Accepted 22 July 2009: First published online 26 August 2009

\begin{abstract}
Objective: We examined the halo effect of a 2-year weight-loss diet trial, the Dietary Intervention Randomized Controlled Trial (DIRECT), on the weight and nutritional patterns of participants' spouses.

Design: DIRECT participants in a research centre workplace were randomly assigned to one of three diets: Low-fat, Mediterranean or Low-carbohydrate. A sample of wives of the DIRECT participants, who attended support update meetings specific to their husband's diet during the first 6 months, were followed for 2 years.

Setting: South Israel.

Subjects: Seventy-four women (mean age $=51$ years, mean BMI $=26 \cdot 6 \mathrm{~kg} / \mathrm{m}^{2}$ ). Results: Among the wives of husbands randomised to the Low-fat, Mediterranean and Low-carbohydrate diet, self-reported weight change was respectively $-1.48 \mathrm{~kg},-2.30 \mathrm{~kg}$ and $-4.62 \mathrm{~kg}$ after 6 months, and $+0.39 \mathrm{~kg},-3.00 \mathrm{~kg}$ and $-2 \cdot 30 \mathrm{~kg}$ after 2 years. Weight loss among wives whose husbands were in the alternative diet groups combined (Mediterranean+Low-carbohydrate) was significantly greater than among wives whose husbands were in the Low-fat group after 6 months $(P=0 \cdot 031)$ and 2 years $(P=0 \cdot 034)$. Overweight wives experienced more weight loss. The weight change of couples was significantly correlated $(r=0.42, P<0 \cdot 001)$. Across all dietary groups, wives had significant improvement in their dietary patterns in all food groups according to their husbands' diets, mainly by a larger significant decrease in carbohydrate consumption in the Low-carbohydrate group $(P=0.013$ compared to Low-fat). Sixmonth weight change among the seventy-four DIRECT participants whose wives took part in the group support sessions was $-5 \cdot 2 \mathrm{~kg}$, compared to $-3 \cdot 5 \mathrm{~kg}$ among the 248 DIRECT participants whose wives did not take part in these sessions $(P=0 \cdot 020)$.

Conclusions: Focusing on the couple as a unit could provide a cost-effective approach to weight-loss programmes.
\end{abstract}

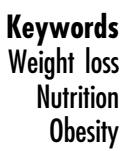

Health promotion for couples includes the opportunity to use the partner's support in encouraging healthy behaviours such as a balanced diet, weight control and physical activity ${ }^{(1,2)}$. Moreover, a dietary intervention programme may exert a beneficial effect on the participant's spouse ${ }^{(3-7)}$. Family environment also appears to significantly affect compliance ${ }^{(8,9)}$. As eating patterns are likely to be similar across family members ${ }^{(10,11)}$, adherence and maintenance of certain eating patterns might be associated with the level of household support for healthy eating $^{(8,9)}$. A combined worksite and family intervention is more successful in changing nutritional patterns than worksite intervention alone ${ }^{(12-14)}$. This strategy might be a promising approach for long-term success in weightloss programmes. However, few studies have explored the mutual effect of specific diet strategies on spouses.

In the 2-year Dietary Intervention Randomised Controlled Trial (DIRECT) ${ }^{(15)}$ among 322 participants, with dropout rates of $5 \%$ after 1 year and $15 \%$ after 2 years, we showed that the Low-carbohydrate and Mediterranean diets are effective alternatives to the Low-fat diet in terms of weight loss, achieving more favourable effects on lipids in the Low-carbohydrate diet and on glycaemic control in the Mediterranean diet. Here we describe a 
parallel study describing the 2-year effect of dietary intervention on weight and nutritional patterns of the spouses of the DIRECT participants across the three dietary arms. We further examined the association between a programme of spouse support, provided through periodic group meetings, and the success of the DIRECT participants in losing weight.

\section{Methods}

The DIRECT and DIRECT-Spouse study population The DIRECT was conducted between July 2005 and June 2007 in a research centre workplace in the south of Israel. Participants ( $86 \%$ of whom were men) were randomly assigned to one of three diets. The Low-fat diet ${ }^{(16)}$ aimed for $30 \%$ of energy from fat, $10 \%$ of energy from saturated fat and $300 \mathrm{mg}$ cholesterol a day, with a total energy intake of $6276 \mathrm{~kJ} / \mathrm{d}(1500 \mathrm{kcal} / \mathrm{d})$ for women and $7531.2 \mathrm{~kJ} / \mathrm{d}(1800$ $\mathrm{kcal} / \mathrm{d}$ ) for men. The Mediterranean $\operatorname{diet}^{(17)}$ aimed for $35 \%$ of energy from fat, mainly from olive oil and nuts, and energy intake restricted to $6276 \mathrm{~kJ} / \mathrm{d}(1500 \mathrm{kcal} / \mathrm{d})$ for women and $7531.2 \mathrm{~kJ} / \mathrm{d}(1800 \mathrm{kcal} / \mathrm{d})$ for men. The Low-carbohydrate $\operatorname{diet}^{(18)}$ aimed for $20 \mathrm{~g}$ of carbohydrate daily for the induction phase (2 months), gradually reaching a specific target carbohydrate level that could maintain the weight loss. Total calories, protein and fat intake were not limited, although participants were counselled to prefer vegetarian sources and to avoid trans fat. The DIRECT-Spouse sub-study included wives of participants in the DIRECT, who share the same household but who were not part of the DIRECT themselves. The DIRECT-Spouse study was approved by the ethical committee of Soroka Medical Center.

\section{Recruitment and follow-up of the study population}

We invited the wives of participants in the DIRECT, and explained the theme and purpose of the sub-study. Those who agreed to participate filled out at baseline (August 2005) a baseline questionnaire that was sent to them personally, and included various demographic and lifestyle characteristics as well as questions regarding their predictions regarding the dieters' success in the DIRECT. Wives were asked to also report their current weight.

Every 2 months during the first 6 months of the DIRECT, participating spouses were invited to a $90 \mathrm{~min}$ support group meeting led by a clinical dietitian specific to the DIRECT participant's dietary arm. The curriculum of these meetings was similar in all groups and included various topics regarding the principles of the DIRECT intervention, learning about healthy nutrition and ways for leading a healthy lifestyle. The aim of the meetings was not to directly treat the spouses, but to update them about the principles of the diet strategy to which their husbands were randomised and to equip the spouses with materials that may enable the wives to support their husbands in their diet. The women were followed for changes of weight, diet and monthly expenses for food at 6 and 24 months.

\section{Statistical analysis}

One-way ANOVA and $\chi^{2}$ tests were used to evaluate the demographic and lifestyle characteristics of the study population. We used non-parametric tests (Wilcoxon Signed test) to assess the weight changes within each dietary subgroup and non-parametric tests (Mann-Whitney test) to evaluate the differences between each group and the reference group (Low-fat diet). We evaluated weight changes of overweight spouses ( $n 40 ; \mathrm{BMI} \geq 25 \mathrm{~kg} / \mathrm{m}^{2}$ at baseline) and compared weight loss across the diet groups using non-parametric tests (Mann-Whitney test). We further evaluated the correlation between weight changes of the DIRECT participants and their wives during the first 6 months, across the three dietary arms. In the DIRECT, we identified the first 6 months as the 'maximal weight-loss phase' and the 7-24 month period as the 'maintenance' phase $^{(15)}$. To evaluate the impact of the spouse support group meetings, we compared the weight change of participants whose wives took part in the sub-study with that of DIRECT participants whose spouses did not take part in the study. The wives completed a food-changes questionnaire (FCQ) ${ }^{(19)} 6$ months after baseline; we modified the 127 -item Israeli FFQ, developed $^{(20,21)}$ and validated $^{(22)}$ in our Nutritional Center, to assess the changes of each food item among the wives, within the first 6 months of the DIRECT. In the FCQ, the spouses were asked whether their own consumption of each specific food item had changed (options: increased/did not change/decreased) since the beginning of the DIRECT. An increase in consumption of a specific food item was scored +1 ; a decrease in consumption of a specific food item was scored -1 ; no difference in consumption was scored 0 . The scores were summed in each food group and divided by the number of items in the group; the results were used in the data analysis. All statistical analyses were performed with the use of SPSS statistical software, version 13 (SPSS Inc., Chicago, IL, USA). $P$ value $<0 \cdot 05$ was considered significant.

\section{Results}

Out of the 322 participants of the DIRECT, 90.5\% were married. Of the 113 wives who completed baseline questionnaires (38.8\% of spouses), seventy-four took part in support group meetings during the first 6 months of the DIRECT ( $n$ 28, 24 and 22 for the corresponding Lowfat, Mediterranean and Low-carbohydrate DIRECT participants' diets). At baseline, their mean age was 50.79 years, and mean BMI was $26 \cdot 6$ (SD $4 \cdot 72) \mathrm{kg} / \mathrm{m}^{2}$. The characteristics of the wives across the randomised assigned dietary arm of the DIRECT participants are described in Table 1. Characteristics were similar across groups. There were no 
Table 1 Baseline characteristics of the wives of the DIRECT participants $(n 74)$

\begin{tabular}{|c|c|c|c|c|c|c|c|c|c|}
\hline & \multicolumn{2}{|c|}{ Low-fat (n 28) } & \multicolumn{2}{|c|}{ Mediterranean ( $n$ 24) } & \multicolumn{2}{|c|}{ Low-carbohydrate ( $n$ 22) } & \multicolumn{2}{|c|}{ Entire group ( $n 74)$} & \multirow[b]{2}{*}{$P(\mathrm{v})^{*}$} \\
\hline & Mean & SD & Mean & SD & Mean & SD & Mean & SD & \\
\hline Age (years) & $50 \cdot 5$ & $6 \cdot 0$ & $52 \cdot 0$ & $5 \cdot 57$ & $49 \cdot 4$ & $6 \cdot 97$ & $50 \cdot 76$ & $6 \cdot 09$ & 0.645 \\
\hline Weight (kg) & $67 \cdot 8$ & $10 \cdot 51$ & $73 \cdot 1$ & $15 \cdot 92$ & $73 \cdot 18$ & $14 \cdot 07$ & $70 \cdot 93$ & $13 \cdot 53$ & 0.329 \\
\hline \multirow[t]{2}{*}{ BMI $\left(\mathrm{kg} / \mathrm{m}^{2}\right)$} & $24 \cdot 9$ & $3 \cdot 69$ & $27 \cdot 81$ & $4 \cdot 98$ & $27 \cdot 79$ & $5 \cdot 14$ & $26 \cdot 66$ & $4 \cdot 72$ & 0.074 \\
\hline & \multicolumn{2}{|c|}{$\%$} & \multicolumn{2}{|c|}{$\%$} & \multicolumn{2}{|c|}{$\%$} & \multicolumn{2}{|c|}{$\%$} & \\
\hline \multicolumn{10}{|l|}{ Education } \\
\hline Primary school & \multicolumn{2}{|c|}{ - } & \multicolumn{2}{|c|}{ - } & \multicolumn{2}{|c|}{ - } & \multicolumn{2}{|c|}{ - } & \\
\hline High school & \multicolumn{2}{|c|}{$50 \cdot 0$} & \multicolumn{2}{|c|}{$54 \cdot 5$} & \multicolumn{2}{|c|}{$52 \cdot 4$} & \multicolumn{2}{|c|}{$52 \cdot 2$} & 0.952 \\
\hline Academic & \multicolumn{2}{|c|}{$50 \cdot 0$} & \multicolumn{2}{|c|}{$45 \cdot 5$} & \multicolumn{2}{|c|}{$47 \cdot 6$} & \multicolumn{2}{|c|}{$47 \cdot 8$} & \\
\hline \multicolumn{10}{|l|}{ Smoking status } \\
\hline Never or past & \multirow{2}{*}{\multicolumn{2}{|c|}{$\begin{array}{l}77 \cdot 8 \\
14 \cdot 8\end{array}$}} & \multirow{2}{*}{\multicolumn{2}{|c|}{$\begin{array}{r}75 \cdot 0 \\
0 \cdot 2\end{array}$}} & \multirow{2}{*}{\multicolumn{2}{|c|}{$95 \cdot 2$}} & \multicolumn{2}{|c|}{$81 \cdot 9$} & \\
\hline Currently $1-5$ cigarettes/d & & & & & \multirow{2}{*}{\multicolumn{2}{|c|}{$\begin{array}{l}4 \cdot 8 \\
-\end{array}$}} & \multicolumn{2}{|c|}{$9 \cdot 7$} & \\
\hline Currently $6-20$ cigarettes/d & \multicolumn{2}{|c|}{$7 \cdot 4$} & \multicolumn{2}{|c|}{$12 \cdot 5$} & & & & & $0 \cdot 152$ \\
\hline Currently more than 20 cigarettes $/ d$ & \multicolumn{2}{|c|}{-} & \multicolumn{2}{|c|}{$4 \cdot 2$} & & & & & \\
\hline Physical activity $\dagger$ & & & & & & & & & \\
\hline None & & & & & & & & & \\
\hline $1-2$ times a week & & & & & & & & & $0 \cdot 174$ \\
\hline 3-4 times a week & & & & & & & & & \\
\hline$>4$ times a week & & & & & & & & & \\
\hline
\end{tabular}

DIRECT, Dietary Intervention Randomized Controlled Trial.

${ }^{*}$ Kruskal-Wallis test for the continuous variables and $\chi^{2}$ for the categorical variables.

+Physical activity $=$ at least $30 \mathrm{~min}$ of vigorous activity a day.

significant differences between the baseline weights of the wives across the three dietary arms $(P=0 \cdot 33)$. Furthermore, no significant differences in demographic characteristics, initial weight and weight loss after 6 months were found between wives who completed the 2-year follow-up and wives who did not (data not shown).

After 6 months, the spouses of the DIRECT participants lost a mean of $2.64 \mathrm{~kg}$ ( $P=0.002$ compared to baseline). Weight loss (Fig. 1a) was $1 \cdot 48$ (SD $2 \cdot 72$ ) $\mathrm{kg}$ for wives of DIRECT participants randomised to the Low-fat diet, $2 \cdot 30$ (SD 2.39) $\mathrm{kg}$ for the Mediterranean and $4.62(\mathrm{SD} 6.56) \mathrm{kg}$ for the Low-carbohydrate diet $(P<0.05$ for all groups, compared to baseline).

We compared the results of the alternative diets (Mediterranean and Low-carbohydrate) to the traditional diet (Low-fat). Weight loss among wives whose husbands were in the Mediterranean diet group $(P=0.064)$ and the Low-carbohydrate diet group $(P=0 \cdot 058)$ tended to be greater, compared to the Low-fat diet-group. Overall, there was significantly greater weight loss among the spouses of the husbands in the two alternative dietgroups combined (Mediterranean + Low-carbohydrate), compared to the traditional Low-fat diet $(P=0 \cdot 031)$. Wives' BMI decreased significantly after 6 months $\left(\Delta \mathrm{BMI}=0.80(\mathrm{sD} 1.91) \mathrm{kg} / \mathrm{m}^{2} ; P=0.001\right.$ compared to baseline), with $\Delta$ BMI of 0.46 (SD 1.03$), 0.62$ (SD 1.06) and $1 \cdot 47(\mathrm{SD} 3 \cdot 16) \mathrm{kg} / \mathrm{m}^{2}$ for wives of participants randomised to the Low-fat, Mediterranean and Low-carbohydrate groups, respectively $(P=0.013,0.024$ and 0.059 , respectively, compared to baseline).

Overall weight loss at 6 months among the overweight spouses ( $n$ 40) with $\mathrm{BMI} \geq 25 \mathrm{~kg} / \mathrm{m}^{2}$ at baseline (mean $\left.\mathrm{BMI}=29 \cdot 5(\mathrm{SD} \quad 4 \cdot 04) \quad \mathrm{kg} / \mathrm{m}^{2}\right) \quad$ was $3.54 \mathrm{~kg} \quad(\mathrm{SD} 5 \cdot 14)$
( $P<0.05$ compared to baseline). For the corresponding Low-fat, Mediterranean and Low-carbohydrate dietary arms, weight loss of overweight spouses was 1.75 (SD $3 \cdot 19), 2 \cdot 96(\mathrm{sD} 2 \cdot 58)$ and $5 \cdot 36(\mathrm{sD} 7 \cdot 45) \mathrm{kg}$, respectively $(P=0.068$ ( $n$ 12),$P=0.08$ ( $n$ 14) and $P=0.042$ ( $n$ 14), respectively, compared to baseline).

A significant correlation (Fig. 1b) was found between weight changes of the seventy-four DIRECT participants and their wives during the first 6 months of the intervention $(r=0.42 ; P<0 \cdot 001)$. The strongest and only statistically significant correlation was for the Lowcarbohydrate diet group $(r=0.57 ; P=0.005)$.

The 6-month weight changes among the seventy-four DIRECT participants whose wives took part in the group sessions was $-5 \cdot 15 \mathrm{~kg}$, compared to the $-3.54 \mathrm{~kg}$ among the 248 DIRECT participants whose spouses did not take part in these sessions $(P=0 \cdot 020)$.

We analysed the changes in the wives' diets (Fig. 2). In all three groups the wives reported lower consumption of saturated fat and trans fat, meat and poultry, bread and pastry, grains, pasta and potato, fruit, sweets and sweetened beverages. In all three groups the wives reported an increased consumption of fish and vegetables. There was a significantly larger decrease in the consumption of grains, pasta and potatoes among wives whose husbands were on the Low-carbohydrate diet, compared to the Low-fat diet $(P=0 \cdot 013)$. Similar trends were reported at 24 months.

After 2 years, weight changes among fifty-three wives were +0.39 ( $\mathrm{SD} 3 \cdot 71) \mathrm{kg}$ among wives of husbands in the Low-fat group ( $n$ 24; $P=0 \cdot 453$, compared to baseline), $-3 \cdot 00$ (SD $6 \cdot 21) \mathrm{kg}$ among wives of husbands in the Mediterranean group ( $n$ 14; $P<0 \cdot 05$, compared to baseline) and $-2 \cdot 30(\mathrm{SD} 2 \cdot 39) \mathrm{kg}$ among wives of husbands in 

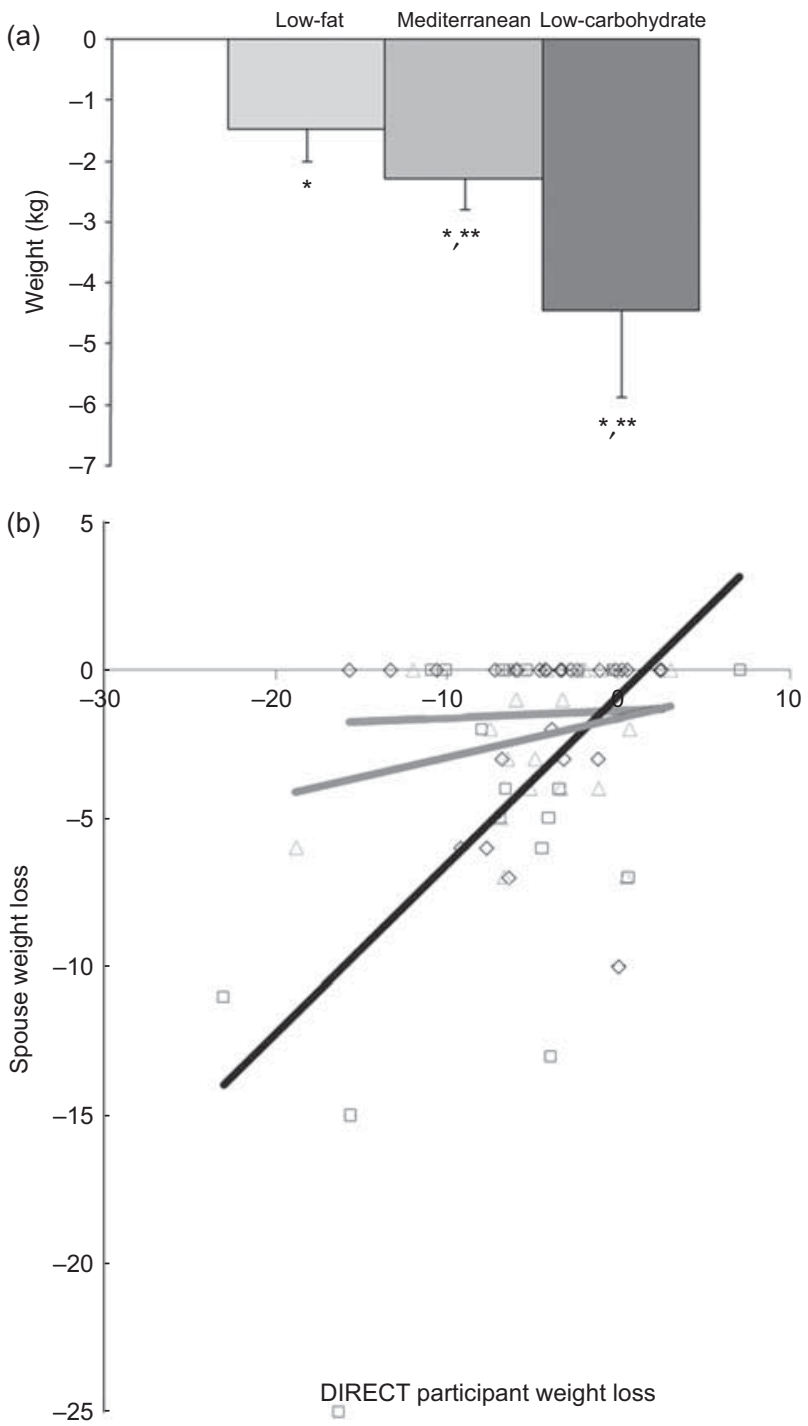

Fig. 1 Weight changes in the Dietary Intervention Randomized Controlled Trial (DIRECT). (a) Changes in weight of wives of participants after 6 months, by randomised dietary arm. Values are means, with an SE of 1 from the mean indicated by error bars. ${ }^{*} n 74, P<0.05$ within diet group, Wilcoxon Signed Ranks Test, as compared to time $0 ;{ }^{\star \star} P<0.06$ in the Mediterranean or Lowcarbohydrate diet group, as compared to the traditional diet Lowfat diet group. (b) Correlation between weight changes among DIRECT participants and their wives after 6 months: (- Lowfat diet group ( $n$ 27, $r=0.418, P=0.842$ ); - , Low-carbohydrate diet group $(n 22, r=0.566, P=0.005)$; $~-$, Mediterranean diet group $(n 23, r=0.322, P=0.16)$

Low-carbohydrate group ( $n$ 15; $P<0 \cdot 05$, compared to baseline). Overall, the significantly greater weight loss among spouses of participants in the two alternative diet groups combined (Mediterranean + Low-carbohydrate), compared to the traditional Low-fat diet, remained after 2 years $(P=0 \cdot 034)$. For DIRECT participants randomised to the Low-fat, Mediterranean and Low-carbohydrate diets, adherence rates at 2 years were $85 \cdot 7 \%, 58 \cdot 4 \%$ and $68 \cdot 2 \%$ $(P<0.05$ between groups). However, spouse populations across the three dietary arms were likely to be similar in baseline characteristics such as weight, education, origin, smoking and physical activity patterns.

The baseline questionnaire included a question 'Regarding the possibility of your husband succeeding and maintaining his diet throughout the DIRECT' (scale from 1 - don't agree to 5 - fully agree). An affirmative answer was a significant predictor for the DIRECT participant's success in losing weight during the first 6 months of the intervention $(\beta=0 \cdot 24 ; P=0 \cdot 046)$.

In the follow-up questionnaires, wives were asked whether their household expenses for food products increased, did not change, or decreased as a result of their husbands' diet. The proportions of wives who reported an increase in monthly food expenses were $25.9 \%$ for Low-fat, $26 \cdot 1 \%$ for Mediterranean and $14 \cdot 3 \%$ for Lowcarbohydrate $(P=0 \cdot 68)$. The rest reported no change.

\section{Discussion}

We evaluated the effect of the DIRECT study on weight loss and nutritional patterns of wives of participants. We found that wives were indirectly affected by the intervention trial of their husbands, by losing weight and improving their nutritional patterns. Overweight spouses at baseline experienced more weight loss. The results suggest that a dietary intervention delivered to one family member may have a beneficial effect on the spouse, and may present a possible ripple effect that may occur as a result of minimal involvement in a weight-loss programme targeting one's spouse. This may provide additional justification for health promotion and dietary modification programmes to target couples as the unit for intervention, as a shared activity.

Our study has several limitations. First, the weight and height of the spouses were self-reported and not directly measured, as was done with DIRECT participants; although this may introduce a possible bias, other studies have previously validated self-reported weights ${ }^{(23,24)}$. Second, the assignment of the spouses study was not randomised and was based on the willingness of the wife to participate. It is possible that these wives were more supportive of their husband's weight-loss efforts than spouses who were unwilling to attend group meetings themselves or complete assessments, likely introducing a self-selection bias. Third, we followed wives only, due to the small proportion of women participating in the DIRECT. The influence of a dietary intervention on spouses of both sexes should be further investigated. Strengths of our study include the long duration of followup, the comparison of the three diet strategies and the close connection our clinical dietitian had with the wives, enabling close follow-up.

Low-carbohydrate diets without energy restriction have earlier been shown to be at least as effective as low-fat, high-carbohydrate diets in inducing weight loss, and were 


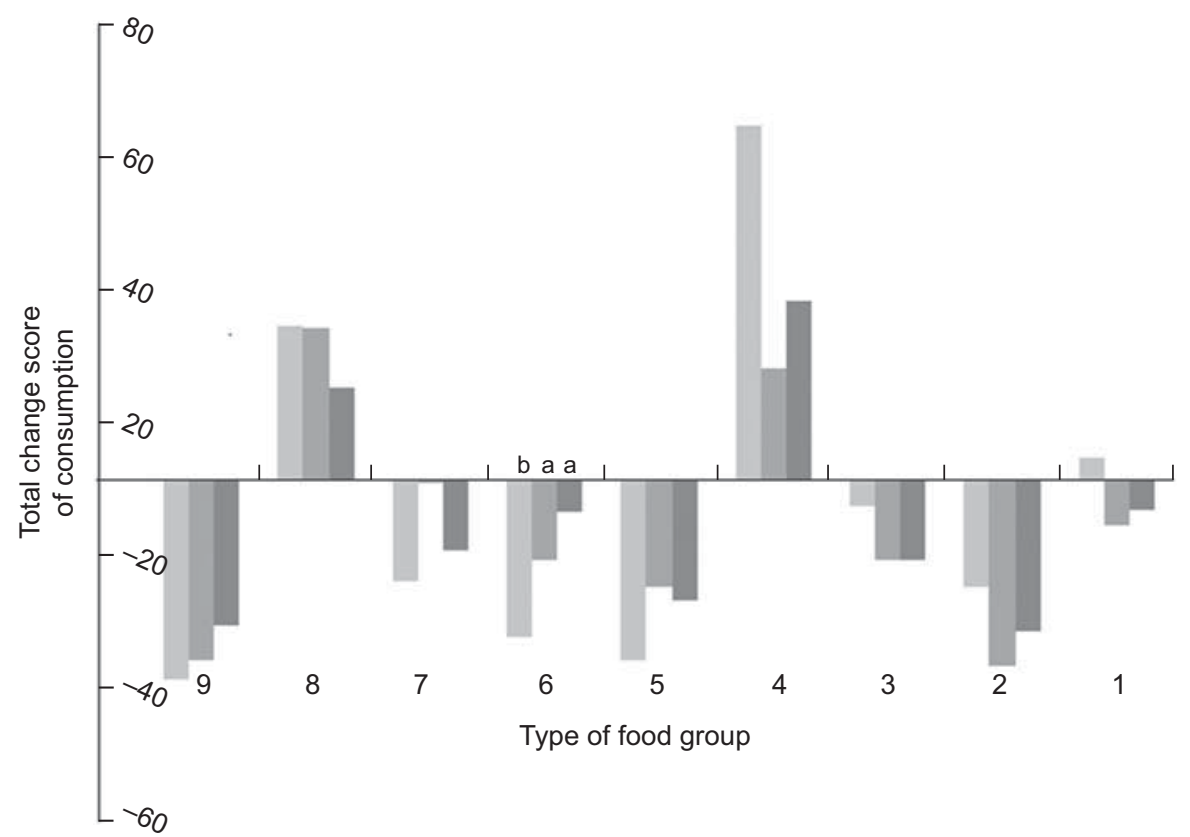

Fig. 2 Changes in nutritional patterns after 6 months among wives ( $n$ 74) of participants in the Dietary Intervention Randomized Controlled Trial (DIRECT), by randomised dietary arm: $\square$, Low-fat ( $n$ 28); $\square$, Mediterranean $(n 24)$; $\square$, Low-carbohydrate $(n$ 22). Food groups: 1 = eggs and dairy, $2=$ saturated fat and trans fat, $3=$ meat and poultry, $4=$ fish, $5=$ bread and pastry, $6=$ grains, pasta and potato, $7=$ fruit, $8=$ vegetables, $9=$ sweets and sweet beverages. The score was calculated for each food item as follows: 'Increased' $=+1$, 'Decreased' $=-1$, 'No change' $=0$. The score for each food group is the sum of all food items in the specific group divided into the number of food items in the food group according to the food change questionnaire, then divided according to the ' $n$ ' of each dietary arm, so each score represents the percentage of change. ${ }^{a, b}$ Values for two diet groups within a row with unlike superscript letters were significantly different $(P<0.05)$

more favourable in overall metabolic outcomes ${ }^{(15,25-27)}$. The strongest correlation between the weight loss of the DIRECT participants and the weight loss of their spouses was found in those randomised to the Low-carbohydrate diet. The changes in nutritional patterns were in accord with the principles of the three diet strategies of the DIRECT participants ${ }^{(15,27-29)}$, and present the possible ripple effect of the trial on the spouses who reported changing their own eating habits. The DIRECT study ${ }^{(15)}$ found that the Mediterranean and Low-carbohydrate diets may be effective strategies in losing weight and maintaining weight loss. Moreover, it was suggested that these diets might be used as specific prescriptions for certain metabolic targets. The findings among the wives suggest that these two alternative diets may also be adapted by spouses as well as the traditional diet and, therefore, may be considered as suitable effective alternative strategies for couples that undertake a joint diet.

DIRECT participants whose spouses took part in the support group meetings lost significantly more weight than the DIRECT participants whose spouses did not participate. Although the present study was not randomised and therefore one may argue that it is hard to use these data to conclude the benefit of involving the spouse in order to raise the participants' success in a dietary intervention, these data are consistent with earlier studies that found that a family intervention was more successful in changing eating patterns than worksite intervention alone ${ }^{(12,13)}$. Moreover, we found that a wife believing in her husband's ability to succeed in his weight-loss project was a significant predictor for the dieter losing weight during the first 6 months of the intervention. These findings suggest a positive relationship between the involvement of the spouse in the intervention and success in weight loss; such findings are consistent with earlier data which recognised social and family support as factors that may raise adherence and encourage health behaviour change in high-risk individuals ${ }^{(5,8)}$ and a recent study reporting the significant role played by the spouse in encouraging the dieter in succeeding in his $\operatorname{diet}^{(7)}$.

Our results suggest an approach of designing dietary intervention programmes that focus on the workplace as well as on the household.

\section{Acknowledgements}

The present study was funded by the following sources: (i) Nuclear Research Center Negev (NRCN); (ii) The Dr. Robert C. and Veronica Atkins Research Foundation; (iii) The S. Daniel Abraham International Center for Health and Nutrition, Ben-Gurion University, Israel. The first two funding sources were not involved in any stage of the design, conduct or analysis of the study, and 
had no access to the study results before publication. The authorship responsibilities were as follows: study design and performance - R.G., D.S., M.J.S. and I.S.; data analysis - R.G.; paper drafting - R.G.; paper review - D.S., M.J.S. and I.S. None of the authors have relationships with companies that make products relevant to the manuscript. The authors are thankful to the 322 DIRECT participants for their consistent cooperation.

\section{References}

1. Burke V, Giangiulio N, Gillam HF, Beilin LJ \& Houghton S (2003) Physical activity and nutrition programs for couples: a randomized controlled trial. I Clin Epidemiol 56, 421-432.

2. Burke V, Giangiulio N, Gillam HF, Beilin LJ, Houghton S \& Milligan RA (1999) Health promotion in couples adapting to a shared lifestyle. Health Educ Res 14, 269-288.

3. Burke V, Mori TA, Giangiulio N, Gillam HF, Beilin LJ, Houghton S, Cutt HE, Mansour J \& Wilson A (2002) An innovative program for changing health behaviors. Asia Pac J Clin Nutr 11, Suppl. 3, S586-S597.

4. White E, Hurlich M \& Thompson RS (1991) Dietary changes among husbands of participants in a low-fat dietary intervention. Am J Prev Med 7, 319-325.

5. Bovbjerg VE, McCann BS \& Brief DJ (1995) Spouse support and long-term adherence to lipid-lowering diets. Am J Epidemiol 141, 451-460.

6. Shattuck A, White E \& Kristal A (1992) How women's adopted low-fat diets affect their husbands. Am J Public Health 82, 1244-1250.

7. Paisley J, Beanlands H, Goldman J, Evers S \& Chappell J (2008) Dietary change: what are the responses and roles of significant others? J Nutr Educ Behav 40, 80-88.

8. Wens LK, Shepherd MD \& Parchman ML (2004) Family support, diet, and exercise among older Mexican Americans with type 2 diabetes. Diabetes Educ 30, 980-993.

9. Schafer RB, Schafer E, Dunbar M \& Keith PM (1999) Marital food interaction and dietary behavior. Soc Sci Med $\mathbf{4 8}$, 787-796.

10. Vauntheir JM, Lluch A, Lecomte E, Artur Y \& Herbeth B (1996) Family resemblance in energy and macronutrient intakes: the Stanislas Family Study. Int J Epidemiol 25, 1030-1037.

11. Macario E \& Sorensen G (1998) Spousal similarities in fruit and vegetable consumption. Am J Health Promot 12, 369-377.

12. Sorensen G, Stoddard A \& Peterson K (1999) Increasing fruit and vegetable consumption through worksites and families in the Treatwell 5-a-day study. Am J Public Health 89, 54-60.

13. Sorensen G, Hunt MK \& Cohen N (1998) Worksite and family education for dietary change: the Treatwell 5-a-Day program. Health Educ Res 13, 577-591.

14. Beresford SA, Thompson B, Feng Z, Christianson A, McLerran D \& Patrick DL (2001) Seattle 5-a-Day worksite program to increase fruit and vegetable consumption. Prev Med 32, 230-238.
15. Shai I, Schwarzfuchs D, Henkin Y et al. (2008) Weight loss with a Low-Carbohydrate, Mediterranean, or Low-Fat Diet. $N$ Engl J Med 359, 229-241.

16. Krauss RM, Eckel RH, Howard B, Appel LJ, Daniels SR \& Deckelbaum RJ (2000) AHA Dietary Guidelines Revision 2000: a statement for healthcare professionals from the Nutrition Committee of the American Heart Association. Circulation 102, 2284-2299.

17. Willett W \& Skerrett PJ (2001) Eat, Drink, and Be Healthy: The Harvard Medical School Guide to Healthy Eating. New York: Simon \& Schuster Source.

18. Atkins RC (2002) Dr. Atkins New Diet Revolution. New York: M. Evans and Company.

19. Shai I, Henkin Y, Weitzman S \& Levi I (2002) Long-term dietary changes after vertical banded gastroplasty: is the trade-off favorable? Obes Surg 12, 805-811.

20. Shai I, Vardi H, Shahar RD, Azrad BA \& Fraser D (2003) Adaptation of international nutrition databases and data entry system tools to a specific population. Public Health Nutr 6, 401-406.

21. Shai I, Shahar DR, Vardi H \& Fraser D (2004) Selection of food items for inclusion in a developed food frequency questionnaire. Public Health Nutr 7, 745-749.

22. Shai I, Rosner BA, Shahar DR, Vardi H, Azrad AB, Kanfi A, Schwarzfuchs D \& Fraser D; DEARR study (2005) Dietary Evaluation and Attenuation of Relative Risk: multiple comparison between blood and urinary biomarkers, food frequency, and 24-hour recall questionnaires: the DEARR study. J Nutr 135, 573-579.

23. Rimm EB, Stampfer MJ, Colditz GA, Chute CG, Litin LB \& Willett WC (1990) Validity of self-reported waist and hip circumferences in men and women. Epidemiology 1, 466-473.

24. Weaver TW, Kushi LH, McGovern PG, Potter JD, Rich SS, King RA, Whitbeck J, Greenstein J \& Sellers TA (1996) Validation study of self-reported measures of fat distribution. Int J Obes Relat Metab Disord 20, 644-650.

25. Dansinger ML (2005) Comparison of the Atkins, Ornish, Weight Watchers, and Zone diets for weight loss and heart disease risk reduction: a randomized trial. JAMA 293, $43-53$.

26. Nordmann AJ, Nordmann A \& Briel M (2006) Effects of low-carbohydrate vs. low-fat diets on weight loss and cardiovascular risk factors: a meta-analysis of randomized controlled trials. Arch Intern Med 166, 285-293.

27. Stern L, Iqbal $\mathrm{N}$, Seshadri P, Chicano KL, Daily DA, McGrory J, Williams M, Gracely EJ \& Samaha FF (2004) The effects of low-carbohydrate versus conventional weight loss diets in severely obese adults: one-year follow-up of a randomized trial. Ann Intern Med 140, 778-785.

28. Gardner CD, Kiazand A, Alhassan S, Kim S, Stafford RS, Balise RR, Kraemer HC \& King AC (2007) Comparison of the Atkins, Zone, Ornish, and LEARN diets for change in weight and related risk factors among overweight premenopausal women: the A TO Z Weight Loss study: a randomized trial. JAMA 297, 969-977.

29. Samaha FF, Iqbal N, Seshadri P, Chicano KL, Daily DA, McGrory J, Williams T, Williams M, Gracely EJ \& Stern L (2003) A low-carbohydrate as compared with a low-fat diet in severe obesity. $N$ Engl J Med 348, 2074-2081. 